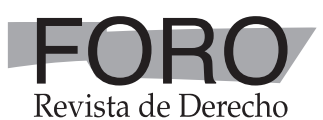

\title{
In dubio pro lector. Ambigüedad narrativa y duda razonable en el relato "En un bosque" de Ryunosuke Akutagawa
}

In dubio pro-reader. Narrative ambiguity and reasonable doubt in the story "In a forest" by Ryunosuke Akutagawa

\author{
Leonardo Valencia \\ Docente de Universidad Andina Simón Bolivar, Ecuador \\ leonardo.valencia@uasb.edu.ec \\ ORCID: https://orcid.org/0000-0003-2180-5775
}

DOI: https://doi.org/10.32719/26312484.2020.33.2

Fecha de recepción: 28 de marzo de 2018

Fecha de aceptación: 29 de junio de 2018 


\section{RESUMEN}

Entre otros, hay dos recursos narrativos para la construcción retórica de la ambigüedad narrativa; el "narrador no fiable" y el "narratario". Este artículo estudia la especificidad combinada de los dos procedimientos en el cuento "En un bosque" (1921) del escritor japonés Ryunosuke Akutagawa para hacer un acercamiento estético a la figura del in dubio pro reo y comprender que en la hermenéutica del juez hay un proceso de lectura e interpretación, distinto al literario, pero que pueden iluminarse comparativamente para reflexionar sobre las pruebas imperfectas de los testimonios en los tribunales y la ambigüedad literaria de los testimonios narrativos, sus respectivas naturalezas y condicionamientos.

PALABRAS CLAVE: literatura y derecho, ambigüedad narrativa, duda razonable, literatura japonesa.

\section{ABSTRACT}

Among others, there are two narrative resources for the rhetorical construction of narrative ambiguity; the "unreliable narrator" and the "fictive reader". This article studies the combined specificity of the two procedures in the story "In a Bamboo Grove" (1921) by the Japanese writer Ryunosuke Akutagawa to make an aesthetic approach to the figure of in dubio pro reo and understand that in the hermeneutics of the judge there is a process of reading and interpretation, different from the literary one, but that can be illuminated comparatively to reflect on the imperfect evidence of the testimonies in the courts and the literary ambiguity of the narrative testimonies, their respective natures and conditionings.

KEYWORDS: Literature and Law, narrative ambiguity, reasonable doubt, Japanese literature.

\section{INTRODUCCIÓN}

$\mathrm{M}$

arguerite Yourcenar advertía que con los autores de Oriente hay una atracción y desconfianza, al mismo tiempo, frente al exotismo: "Siempre es difícil juzgar a un escritor contemporáneo: carecemos de perspectiva. Y aún es más difícil juzgarlo si pertenece a su civilización que no es la nuestra y con lo cual entran en juego el atractivo del exotismo y la desconfianza ante el exotismo". ${ }^{1}$ Aunque el desconocimiento de

1. Marguerite Yourcenar, Mishima o la visión del vacio (Barcelona: Seix Barral, 1985), 9. 
la lengua japonesa y las sutilezas de su cultura son una restricción para los occidentales, hay un grupo de escritores japoneses que facilitaron el encuentro volviéndolo más complejo por una luz más bien sutil y velada.

Las pasiones literarias inglesas, francesas y norteamericanas de Akutagawa, Mishima, Tanizaki o, contemporáneo nuestro, Haruki Murakami, han imbuido sus propias obras y permiten un puente propicio de ida y vuelta. José Kozer recordaba al biógrafo Yoshida Seiichi quien decía que hay sesenta y dos cuentos de Akutagawa con fuentes reconocidas en Dostoievsky, Swift, Poe, Strindberg, Gogol o Anatole France, entre otros, además de las de su tradición. Los lectores occidentales podrán percibir esas correspondencias y afinidades que dan una breve luz exterior para asomarse al oscuro centro del escritor. Así como asombra esta capacidad de diálogo como virtud -los nacionalismos excluyentes se opacan en esa puntual tradición enriquecida de Japóntambién se puede constatar que el puente, aunque firme, sigue siendo estrecho: la obra de Akutagawa no es lo suficiente conocida en lengua española porque apenas se han traducido selecciones muy breves, cuando su obra incluye ocho libros de cuentos publicados en vida, además de libros de ensayos y poesía y de traducciones de Yeats y Anatole France. Su obra completa tiene veinte volúmenes. En un prólogo de Haruki Murakami a una selección de cuentos de Akutagawa, señaló que produjo mucho y que buena parte de sus cuentos "no fueron particularmente destacables", pero también advierte que "si de cien relatos, diez sobreviven para ser leídos por las generaciones siguientes, es un éxito enorme". ${ }^{2}$ Mucho antes, Borges prologó otra de estas selecciones, comentando "Kappa" y "Los engranajes" y acertó al describir la peculiaridad de Akutagawa por "cierta tristeza reprimida, cierta ligereza de pincelada" así como que "la extravagancia y el horror están en sus páginas, pero no en el estilo, que siempre es límpido". ${ }^{3}$ Esto precisamente, y que sean narraciones y no poemas, hace posible el acercamiento a la escritura de Akutagawa con una menor pérdida residual en la brevedad de su obra asequible en español.

Aun así, lo que el lector profano de Occidente conoce del sombrío escritor está iluminado con una luz deslumbrante. Me refiero a la película Rashomón de Akira Kurosawa, basada en el cuento homónimo del escritor y estrenada en 1950. Existe incluso el llamado efecto Rashomón, esa incertidumbre sobre la imposibilidad de concluir una verdad, que tanto atrae a antropólogos, neurocientíficos, cineastas, juristas, sociólogos,

2. Ryunosuke Akutagawa, Belleza de lo brutal (Yasei No Utsukushisa): diez cuentos, prólogo de Haruki Murakami (Barcelona: Días contados, 2011), 16.

3. Ryunosuke Akutagawa, Kappa. Los engranajes, prólogo de J. L. Borges (Buenos Aires: Mundonuevo, 1959), 12. 
historiadores o filósofos. ${ }^{4}$ La película no solo se basa en este cuento, sino también en otro de Akutagawa, titulado "En un bosque" o "En un bosquecillo", o incluso "En una arboleda de bambú" ("In a Bamboo Grove" según Jay Rubin). El recurso narrativo fundamental de la película es la de este cuento y no del titulado "Rashomón". Kurosawa ensambla ambos cuentos, y acierta por otras razones narrativas, esta vez cinematográficas. Solo que esa adaptación borra parte del texto, en la que me quiero detener.

"En un bosque" reúne siete puntos de vista distintos sobre un asesinato, muchos de ellos opuestos y contradictorios. Dan su testimonio, en orden de aparición, un leñador, un monje budista, un gendarme, la madre de Masago, un delincuente (Tajomaru), la misma Masago y, como cierre inesperado y turbadoramente verosímil, un espiritista a través del cual habla el muerto. Todos ellos, salvo el espiritista, se dirigen al comisario Mayor de Policía, constituido como narratario de la historia, es decir, un personaje implicado, sin voz, a quienes hablan los personajes respondiendo a sus preguntas tácitas de investigador.

El cuento "Rashomón", en cambio, tiene un solo y nítido punto de vista. El protagonista está bajo la gran puerta de Rashomón, al sur de Kyoto, en medio de un ambiente lluvioso y desolado, con varios muertos, donde medita sobre su mala suerte. En el cuento el personaje descubre a una anciana que arranca los cabellos a varios muertos. Él la pone en evidencia, la encara y, sin transición, le roba su kimono. No ocurre nada más. El mérito del cuento no es tanto la anécdota sino la atmósfera opresiva de un mundo destruido. Kurosawa elimina a la anciana y se queda con el escenario desolado y estático, perfecto para convertir la película, desde esa atalaya, en una gran retrospección sobre el asesinato del otro cuento. ${ }^{5}$ Por esto abordo el cuento "En un bosque" y no la película. Mi objetivo es recorrer su construcción para percibir el aspecto final de la historia, que no es tanto contar el asesinato como su investigación policial, que la película de Kurosawa minimiza. Y también, a través del mecanismo del narrador no fiable y del narratario, y de su específica interacción en este cuento,

4. Blair Davis, Robert Anderson y Jan Walls, eds., Rashomon Effects: Kurosawa, Rashomon and Their Legacies (Abingdon: Routledge, 2015).

5. Una de las características para la construcción narrativa de una retrospección consiste en contar con un punto relativamente quieto en el que se deberán tomar decisiones, o se aguarda un acontecimiento, y que permiten excavar en las causas y antecedentes. Estático es el momento en el que la Eveline de Joyce, en uno de los cuentos de Dublineses, decide si marcharse o no de Irlanda, o cuando el protagonista del cuento "La breve vida feliz de Francis Macomber", de Hemingway, evalúa su cobardía en la cacería del león mientras espera en la tienda de campaña hasta altas horas de la madrugada, mientras su mujer le es infiel con el guía de cazadores. O como cuando el protagonista del cuento de Rulfo, “iDiles que no me maten!”, espera la sentencia del capitán del ejército revolucionario mientras evoca un acontecimiento remoto en el cual asesinó a un hombre y lo daba por olvidado por la ruina en la que se convirtió su vida. 
acercarme a una lectura del concepto del in dubio pro reo volcado hacia la hermenéutica del juez y del lector.

\section{EL NARRADOR NO FIABLE Y EL NARRATARIO}

De larga data en la tradición narrativa, el concepto del narrador sospechoso o no fiable (unreliable narrator) fue estudiado en la segunda mitad del siglo XX por teóricos como Wayne C. Booth en su clásico The Rethoric of Fiction, de $1961,{ }^{6} \mathrm{y}$ ha tenido distintas revisiones críticas, como la de Ansgar Nünning ${ }^{7}$ basadas sobre todo en el problema de la definición del autor implicado al que lo vincula Booth. Martin y Phelan ${ }^{8}$ establecen seis tipos de no fiabilidad: underreporting, misreporting, underregarding, misregarding (misevaluating), underreading y misreading.

Un narrador no fiable es aquel que puede llegar a mentir o que oculta, distorsiona, dramatiza o escamotea información en su relato con un propósito inmediato y, casi siempre, uno ulterior. El inmediato puede ser una forma de captatio benevolentiae por medio de la cual evita interferencias con la credibilidad y simpatía del lector. Y el ulterior o final, puede constituir una especie de catarsis o aceptación personal, y también, ya en el plano del autor, la posibilidad de giro impactante final para la historia. Respecto a ganar la simpatía del lector, o evitar su rechazo, uno de los ejemplos contemporáneos más destacados, y que ha concitado la revisión crítica del concepto del narrador no fiable, es el de la novela Los restos del día de Kazuo Ishiguro. El narrador, Stevens, un puntilloso mayordomo inglés, evoca los años de servicio a un lord. En la actualidad de su relato trabaja para un millonario norteamericano, en la misma casa de su antiguo patrón, y cuenta su pasado incidiendo en la naturaleza exigente de su trabajo de mayordomo. En el texto, veladamente se descubre que se está dirigiendo a unos jóvenes mayordomos a los que cuenta su experiencia. Lo que escamotea Stevens

6. "I have called a narrator reliable when he speaks for or acts in accordance with the norms or the work (which is to say the implied author's norms), unreliable when he does not. It is true that most of the great reliable narrators indulge in large amounts of incidental irony, and they are thus "unreliable" in the sense of being potentially deceptive. But difficult irony is not sufficient to make a narrator unreliable". Wayne C. Booth, The rethoric of fiction (London: The University of Chicago Press, 1983), 158-9.

7. Ver Ansgar Nünning, "Reconceptualizing Unreliable Narration: Synthesizing Cognitive and Rhetorical Approaches", en A Companion to Narrative Theory, ed. James Phelan y Peter J. Rabinowitz (Malden: Blackwell Publishing, 2005). Nünning plantea la poca claridad y la metodología insatisfactoria de las teorías convencionales sobre la narración no fiable respecto a la manera en cómo se puede percibir la no fiabilidad durante el proceso de lectura.

8. Mary Patricia Martin y James Phelan, “The Lessons of 'Weymouth': Homodiegesis, Unreliability, Ethics, and The Remains of the Day", en Narratologies: New Perspectives on Narrative Analysis, ed. David Herman (Columbus: Ohio State University Press, 1999), 88-109. 
es que, detrás de su exigencia laboral, es reacio a admitir que por dedicarse tanto a trabajar no hizo ninguna consideración de que el lord al que servía había sido un simpatizante y colaborador de los nazis.

En el plano estético, el narrador no fiable activa en el lector una agudeza para percibir emociones e ideas que el mismo personaje narrador parece no tener, y, al mismo tiempo, induce a una especie de compasión por la comprensibilidad mayor que el lector desarrolla. Es quizá uno de los mayores logros novelísticos alcanzar esa comprensión sugerida sobre el personaje y la historia, sobre los equívocos en los que incurren estos, sin que se requiera la explicitación del mensaje.

Respecto al concepto de narratario, su planteamiento teórico fundacional lo hizo Gérard Genette en Figuras III, ${ }^{9}$ donde lo homologó al narrador en el mismo plano narrativo. Un narrador se dirige a alguien que está en su mismo plano ficcional. ${ }^{10}$ Tiene un papel activo en el sentido que condiciona, dirige, estimula o reprime la voz del narrador que le está hablando. El ejemplo clásico de narratario es el de las Mil y una noches, porque la narradora, Sherezade, no solo cuenta cientos de historias, sino que se las cuenta al Califa para salvar su propia vida, porque todas las mujeres que están con él mueren al día siguiente, pero ella le sostiene la intriga interrumpiendo sus relatos.

Con estos dos breves elementos, quiero considerar la particularidad de la interacción entre los narradores no fiables y el peso específico de un narratario que no es un simple destinatario, sino un policía que remarca todavía más su injerencia tácita en el texto.

\section{ENTRANDO EN EL BOSQUE}

Los tres primeros testimonios de "En un bosque" son de personajes ajenos a los protagonistas, pero que vieron el lugar del crimen o conocen a uno de los personajes. El leñador cuenta cómo encuentra el cadáver. El monje budista cuenta cómo se encontró horas antes con el samurái y su mujer, y concluye: "En ningún momento pude imaginarme que ése sería su destino. En verdad la vida del hombre es efímera como el rocío matutino o el relámpago. No tengo palabras para expresar la pena que me embarga". El gendarme da cuenta de la captura de Tajomaru, un forajido de los alrededores de Kyoto. Conforme avanza el cuento llegamos a los personajes implicados, la madre de Masago y el resto. En el testimonio del leñador y el monje budista se percibe el recurso del narratario, consistente en que el discurso de los personajes,

9. Gérard Genette, Discours du récit (París: Éditions du Seuil, 2007).

10. "Como el narrador, el narratario es uno de los elementos de la situación narrativa, y se ubica necesariamente en el mismo nivel diegético". Ibíd., 272. 
sus propias palabras y su actitud, los retrata, sea por intimidación ante la autoridad o por la correspondencia con su oficio, personalidad o actitud. Como el testimonio del leñador no es muy extenso, lo cito completo:

Sí, señor. Fui yo quien encontró el cadáver. Había salido de mañana a talar como siempre la cuota diaria de cedros cuando encontré el cadáver en un soto que hay en una depresión de las montañas. ¿El lugar preciso? A unos ciento cincuenta metros del camino de coches de Yamashina. Un bosquecillo apartado de cedros y bambú.

El cadáver yacía boca arriba con el quimono azul claro y una cofia estilo Kyoto toda arrugada. La hoja de la espada le había traspasado el pecho de un solo golpe. A su alrededor, cañas de bambú con las flores salpicadas de sangre. No, la sangre ya no corría. Creo que la herida estaba seca. Y también había un moscardón prendido a la herida que apenas me sintió llegar.

¿Que si vi una espada o algo por el estilo?

No, señor, no vi nada. Solo una soga al pie de un cedro que por ahí había. Y... Bueno, además de la soga me encontré un peine. Eso es todo. Parece que se libró una batalla antes de que lo asesinaran porque a su alrededor se veía la yerba pisoteada y las cañas de bambú estaban desbaratadas.

¿Que si había un caballo cerca?

No, señor. Es difícil que un hombre se meta por esos matorrales. Imagínese entonces un caballo. ${ }^{11}$

El leñador es lacónico y puntual, sin las divagaciones metafísicas que hace el monje budista, y es de notar que su testimonio sugiere un velado temor de que se le pida explicaciones de por qué estaba en ese bosque, por si estuviera talando donde no le es permitido. A la pregunta tácita del comisario Mayor de Policía responde que no ha visto ningún caballo ni ninguna espada. Dice que "había salido de mañana a talar como siempre la cuota diaria de cedro cuando encontré el cadáver". Subrayo sus palabras porque la actitud es defensiva, se anticipa o justifica de antemano. Está inhibido ante la autoridad. Pero luego dice algo que podría levantar las sospechas del lector (y del comisario). Si respondió que no vio ninguna espada, ¿por qué había dicho antes, al encontrar el cadáver, que "la hoja de la espada le había traspasado el pecho de un solo golpe”? ¿Por qué concluye que hubo un combate? La observación es muy precisa, y a menos que se haya detenido a observar el cadáver con escrúpulo forense, más bien parece ser un lapsus que pone en evidencia que el leñador quizá vio el enfrentamiento y el asesinato, pero se mantuvo oculto por su propia seguridad. No habla más de la cuenta para no comprometerse como testigo presencial ante el asesino. En el caso del monje budista llama la atención su precisión al describir que el samurái llevaba un

11. Ryunosuke Akutagawa, Rashomón y otros cuentos (Madrid: Miraguano, 1987), 7. 
carcaj con veinte flechas, pero poco antes, luego de decir que estimaba la estatura de la mujer en un metro veinticinco y que llevaba un kimono lila, se excusa argumentando que "como soy sacerdote budista no me fijé con detenimiento". Sí que se fijó en la mujer, es un observador culto y preciso, pero quiere demostrar su pudor de monje respecto a la mujer delante de una autoridad, el comisario mayor de Policía que lo está interrogando. El narratario es un condicionante del lenguaje del narrador, porque sus palabras varían en función de a quien se está dirigiendo.

El dato del color azul del kimono del samurái asesinado, es diferente de otros dos testimonios. El gendarme y Masago dicen que era Tajomaru quien llevaba un kimono azul. El monje budista dice que la mujer llevaba un kimono lila y Tajomaru que quien llevaba el kimono lila era el samurái asesinado. Estas contradicciones, sumadas a que los testimonios están condicionados por la presencia de la autoridad y, sobre todo, a que cada quien se atribuye el asesinato o el suicidio, son los que establecen una duda razonable. Quizá la única certidumbre la podría dar el testimonio del gendarme que ha atrapado a Tajomaru. Incluso ostenta un cierto orgullo. No tiene nada que temer ante el comisario Mayor de Policía porque su oficio es el de rendir cuentas. Explica que hubo dos asesinatos de mujeres el año pasado y que se sospecha de Tajomaru. Su testimonio prepara el siguiente, el del delincuente.

La versión de Tajomaru es uno de los momentos más críticos del cuento porque el misterio parece aclararse. Es el único personaje que no tiene nada que perder, porque es un delincuente con antecedentes y ha sido capturado. Su testimonio empieza así:

A él lo maté, pero a ella no. ¿Qué dónde está [ella]? Yo qué sé. Un momento, un momento.

No hay tortura que me vaya a hacer confesar lo que no sé. Ahora que las cosas han llegado a este extremo lo diré todo. ${ }^{12}$

Este párrafo resuelve su postura. La afirmación inicial sería concluyente: se declara culpable y, por si acaso, se exime de la responsabilidad de lo que le pudo pasar a la mujer, porque en el momento de dar su testimonio se le ha preguntado por su paradero. Cuando se anticipa a declarar que ninguna tortura le hará declarar lo que no sabe, quiere evitar ese trance. Y concluye con una ambigua parresia: contará todo. ${ }^{13}$ $\mathrm{Su}$ testimonio es la parte más extensa del cuento. En su versión explica cómo engañó a la pareja tentándolos con que había descubierto un tesoro y así los alejó del camino

12. Ibíd., 10.

13. Ver la clase del 10 de marzo de 1982 en Michel Foucault, La hermenéutica del sujeto: curso en el Collége de France (1981-1982) (Buenos Aires: Fondo de Cultura Económica, 2002) y la clase del 12 de enero de 1983 en Michel Foucault, El gobierno de sí y de los otros: curso en el Collége de France (1982-1983) (Buenos Aires: Fondo de Cultura Económica, 2009). 
principal. Lleva primero al hombre al centro del bosque, lo ata, y luego trae a la mujer. Cuando ella lo ve atado, ataca a Tajomaru con un espadín, pero este la doblega. Tajomaru pasa muy rápidamente por la violación, diciendo: "por fin pude saciarme sin tener que matar al marido". Y a continuación añade: "Sí... sin tener que quitarle la vida". En este punto el delincuente desarrolla un discurso que más que para atenuar su culpa, busca un resquicio de honor afirmando que no mató al marido fríamente. Explica que la mujer, luego de ser violada, le exigió que mate al marido o que se mate él mismo porque no puede resistir a la deshonra, y que ella se quedaría con el vencedor. "No quería recurrir a procedimientos ilegítimos para hacerlo", afirma Tajomaru. Desata entonces al marido y combaten. "Ya saben cómo acabó el combate -explica Tajomaru-. Fue el golpe veintitrés..., no lo olvide, por favor. Todavía me cuesta trabajo creerlo. No hay nadie bajo el sol que haya cruzado veinte golpes de espada conmigo". En el ajetreo del combate la mujer desapareció y él ya no la volvió a ver. Esta estratagema del discurso de Tajomaru apela, como dijimos, a restituir alguna forma de honor propio de la cultura japonesa, pero también es una manera de evitar la tortura para conocer el paradero de la mujer. Abre también un escenario perverso: que ella haya pedido la muerte de su marido. Y también un punto de incertidumbre: Tajomaru nunca dice el color de los respectivos kimonos.

Aquí el cuento se complica. El siguiente testimonio es el de la mujer, Masago. Según ella, Tajomaru llevaba un kimono azul, coincidiendo con la versión del gendarme, mientras que dice que su marido tenía un kimono lila, invalidando la descripción del leñador, según el cual el muerto vestía de azul. Pero lo más importante radica en que niega la versión de Tajomaru de que había asesinado al samurái. Más bien lo que termina por concluir ella es que, luego de la vergüenza de la violación, se queda desolada cuando descubre una mirada fría por parte de su marido, y le termina proponiendo a él que no podrá sobrevivir a esa vergüenza y que lo mejor era que ambos se suiciden. Cito la parte decisiva de su testimonio:

No pude hablar más. Él me seguía mirando con asco y desprecio. Busqué su espada con el corazón haciéndoseme pedazos. Seguro que el ladrón se la había llevado. No pude encontrar la espada en el bosquecillo, ni el arco y las flechas. Por suerte mi espadín yacía a mis pies. Alzándolo por encima de la cabeza exclamé una vez más: "Entrégame la vida. Y yo te seguiré". Al oír esas palabras movió los labios con dificultad. Como tenía la boca atiborrada de hojas, su voz era, por supuesto, inaudible. Pero entendí de un golpe sus palabras. En su desprecio, aquella mirada imperturbable decía: "Mátame". Sin comprender exactamente lo que hacía enterré el espadín en su pecho, atravesándole el quimono lila. ${ }^{14}$

14. Akutagawa, Rashomón y otros cuentos, 15-6. 
Y afirma al final: "Maté a mi propio marido. El ladrón me violó. ¿Qué puedo hacer?"

Bajo el shock de la violación, ella reaccionó de esa manera. Pero entonces surgen las preguntas: si ella afirma haberlo matado con el espadín, ¿por qué Tajomaru dice que fue él quien lo asesinó con la espada? Aquí es donde el lector empieza a dudar. La muerte es un hecho, pero el culpable es un enigma. Revisando la versión de Tajomaru, atribuirse una muerte es un precio demasiado alto para evitar la tortura. La única explicación es que, al cargar tantas culpas por delitos previos, esta muerte habría sido una más dentro de una inevitable condena a muerte. Sin embargo, no pierde su condición enigmática, en la medida que se haga caso a la afirmación de asesinato por parte de la mujer. Y en lo que respecta a ella, atenuada también está su situación por el shock de la violación. El alarde de Tajomaru de que lo venció con el golpe veintitrés es sospechoso por otro motivo que Kurosawa amplía en su película: sí hubo una pelea, pero no fue como lo contó el delincuente. No fue un combate épico. Más bien ambos hombres sintieron miedo en el combate a muerte, fue una pelea simple y Tajomaru venció por casualidad.

Hay un testimonio anterior, ubicado entre el del gendarme y Tajomaru, que es el de una mujer anciana, la madre de Masago. Aporta datos concretos, el nombre del samurái, Kanazawa no Takehiko, y el de su hija Masago, y que tiene diecinueve años y que es una mujer impetuosa. En su declaración afirma: "no me cabe la menor duda que (Masago) no conoció a otro hombre que no fuera Takehiko", que "me resigno a perder a mi yerno" y, finalmente, "cómo odio al Tajomaru ese o como se llame el ladrón". En el contexto no fiable de los otros testimonios -enunciados por narradores, ya que hablamos de un cuento- las contradicciones emergentes iniciales despiertan sospecha. ¿Por qué afirma la madre que su hija no ha conocido a otro hombre? ¿Es que acaso Masago había sido amante de Tajomaru y lo está encubriendo para que reciba la pena capital? ¿Es que Tajomaru preparó la emboscada para matar al marido y quedarse con Masago de mutuo acuerdo previo con ella? ¿O será más bien que Masago cometió alguna infidelidad y recurre a Tajomaru para urdir un asalto y matar al marido antes que él la desprecie públicamente? ¿Cuál era el propósito del viaje del samurái y Masago?

El cuento termina con un giro inesperado. El último testimonio es el de un espiritista a través del cual habla el muerto. Afirma que luego de la violación, Tajomaru le dice a ella que ya no se podrá llevar bien con su marido y que se case con él. A lo que la mujer reacciona pidiéndole que mate a su marido. "Mientras [él] viva no podré casarme contigo. ¡Mátalo!”. Tajomaru palidece, asombrado por la petición, y cambia de actitud, dirigiéndose al hombre: "Decide. ¿La mato o la dejo viva?". Ella quiere huir, él intenta sujetarla pero se le escapa de las manos. Una vez que se ha marchado, Tajomaru finalmente libera al hombre y se marcha. Torturado por lo que ha ocurrido, el hombre coge el espadín de su mujer y se suicida. Poco antes de morir, percibe que alguien "sacó suavemente el espadín que me había enterrado en el pecho". Y luego 
vienen las magistrales líneas finales: "Y de una vez por todas me hundí en la oscuridad del espacio".

De manera que, según los implicados, Tajomaru dice que él mató al hombre; Masago dice que fue ella quien lo mató, y finalmente el muerto revela que fue él quien se suicidó. ¿Quién es el culpable?

Antes de responder hay que dejar en claro el último punto de incertidumbre que aparentemente queda anulado, y que revela que la disposición formal es clave para lograr la inmersión ficcional, y es que el testimonio del muerto, aunque imposible es verosímil, y lo es porque es tal la turbación del lector ante las contradicciones y la incertidumbre, que este se aferra al único punto de vista de quien ya no tiene nada que perder porque lo ha perdido todo y que, a su manera, es el que reclama justicia, el mismo muerto. Pero mientras el cuerpo de un muerto es la evidencia de un hecho, su testimonio verbal es una imposibilidad: quien habló no es el muerto sino un espiritista. Akutagawa no pone en el pretítulo que el espiritista está dando su testimonio frente al comisario Mayor de Policía. Solo dice: "Versión del occiso a través de un espiritista". La diferencia es decisiva. Un policía no se va a fiar de un médium. No tiene validez probatoria. Y, sin embargo, en el cuento sí es posible. Esta coda calma al lector desorientado en la investigación, da un giro a los personajes, los hace redondos en el sentido clásico del término porque no resultan predecibles y más bien se manifiestan ricos y ambiguos. El samurái, luego de la violación de su mujer y que ella le pidiera a Tajomaru que lo mate, se termina suicidando con el espadín. Esta revelación final abre otro horizonte de preguntas: si el testimonio del muerto exime a Tajomaru, ¿no será que el espiritista lo está encubriendo? ¿Encubre también a la mujer que se atribuye el asesinato del samurái?

La capacidad sintética de Akutagawa logra esto en un cuento que no llega a una decena de páginas. No significa que necesariamente el lector crea en la última versión. La atenúa gracias al elemento fantástico. Pero ¿qué ocurre con el personaje silencioso del cuento, el comisario Mayor de Policía. ¿En qué puede creer él? Y el juez o el tribunal que debe juzgar a Tajomaru y a la mujer, ¿cómo va a decidir ante las contradicciones y la invalidez legal que tiene el testimonio de un espiritista? ¿O es más bien el juez o el tribunal quienes, como los lectores, aunque quieren resolver el enigma, van a quedar exentos de cerrar el sentido de una manera definitiva, a riesgo de condenar a un inocente?

\section{IN DUBIO PRO REO... ¿IN DUBIO PRO LECTOR?}

Cesare Beccaria, en su tratado De los delitos y de las penas estableció las distinciones entre las pruebas perfectas e imperfectas para un juicio: 
Una sola de las primeras [las pruebas perfectas] es suficiente para la condena, de las segundas se necesitan tantas como basten para formar una prueba perfecta, es decir, que si por cada una de estas en particular es posible que alguien no sea culpable, por su convergencia en el mismo sujeto es imposible que no lo sea. Adviértase que las pruebas imperfectas de las que el reo puede justificarse y no lo haga debidamente se convierten en perfectas. Pero es más fácil sentir la certeza moral de las pruebas que definirla con exactitud. ${ }^{15}$

Mientras que una sola prueba baste para condenar al acusado y se la tiene por perfecta, la reunión de pruebas imperfectas no sirve para condenar, pero sí para mantenerlo como reo. Añade Beccaria que si el acusado puede justificarse frente a una prueba imperfecta y no lo hace, esta se convierte en perfecta. Más allá de ese axioma básico de la hermenéutica del juez, quiero destacar la observación final de Beccaria, cuando dice que una certidumbre moral sobre las pruebas es más fácil sentirla -por parte de quien debe juzgar- que definirla. En realidad es un problema ya tratado en la antigüedad. En el siglo II D. C., el escritor Aulo Gelio registró una de sus experiencias como juez en el capítulo 2 del libro XIX de las Noches áticas, titulado "Disertación de Favorino respondiendo a una pregunta mía sobre la función de juez”. Allí explica que consultó a Favorino sobre un caso de reclamación de dinero, en el que una de las partes, la reclamante, tiene una reconocida honorabilidad, mientras que el reclamado no la tiene, pero afirma que ya devolvió el dinero. El reclamante no tiene ningún tipo de documentación de prueba del dinero a pagar. El problema es que Aulo Gelio acepta que está influido por el prestigio del reclamante. Favorino le recomienda que tenga cuidado, porque mientras unos jueces tratan de descubrir los sentimientos de las partes, otros:

los jueces considerados más tranquilos y sosegados afirman que, mientras se dirime el pleito, antes de pronunciar sentencia, el juez no debe manifestar su sentir cuantas veces se siente conmovido por la proposición de un argumento; ${ }^{16}$ pues lo que sucedería - dicen- es que, a causa de la variedad de proposiciones y de argumentos, el juez se vería precisado a soportar reacciones muy diferentes, y daría la impresión de que sus opiniones y sus intervenciones resultan ser muy distintas a lo largo de una misma causa y de unas mismas circunstancias. ${ }^{17}$

15. Cesare Beccaria, De los delitos y de las penas (Madrid: Trotta, 2011), 157.

16. Conviene fijarse que al eliminar Akutagawa las reacciones del comisario de policía frente a los testimonios, evita que el lector encuentre una apoyatura o sesgo sobre cómo valorar la información que proporcionan. Esta frialdad narrativa y escamoteo son los que dan mayor intensidad dramática a la irresolución de la investigación y que permite la vía para suspender la incredulidad del lector cuando asoma la versión del espiritista.

17. Aulo Gelio, Noches áticas, introducción, traducción, notas e índices de Manuel-Antonio Marcos Casquero y Avelino Domínguez García (León: Universidad de León, 2006), 112. 
El consejo final de Favorino a Aulo Gelio es que le dé su voto de confianza al reclamante, por su honorabilidad. Pero Aulo Gelio no está convencido y llega a las líneas de donde nace el concepto del non liquet (no está claro), cuando dice: "no pude convencerme de que debía dictar sentencia absolutoria, por lo que juré que yo no tenía claros los criterios (et propterea iuravi mihi non liquere) al respecto y fui liberado de aquella función de juez". ${ }^{18}$

Es decir, Aulo Gelio se exime porque no hay pruebas y porque tiene una duda razonable al respecto. Por más honorabilidad que tenga el reclamante, no tiene ningún documento que pruebe su reclamación. Aunque tiene duda respecto al caso, no duda de que pueda fallar objetivamente. Y aunque el reclamado es un individuo de mala fama, debe protegerlo en función de esa duda y esa falta de pruebas. Hay un matiz que James Q. Whitman explica en "The Origins of Reasonable Doubt", cuando señala que la finalidad de la duda razonable no es tanto defender el derecho del acusado, sino la conciencia del juez. Aulo Gelio lo advierte sutilmente, se justifica y se escuda en aspectos más complejos como el riesgo de estar condenado a alguien por cuestiones morales, sin pruebas. Whitman señala que la duda razonable tendría que ver con el desarrollo del cristianismo, centrando la preocupación en salvar el alma del juez en el caso de equivocarse en la condena de un inocente:

Instead, it had a significantly different, and distinctly Christian, purpose: The "reasonable doubt" formula was originally concerned with protecting the souls of the jurors against damnation. Convicting an innocent defendant was regarded, in the older Christian tradition, as a potential mortal sin. The purpose of the "reasonable doubt" instruction was to address this frightening possibility, reassuring jurors that they could convict the defendant without risking their own salvation, as long as their doubts about guilt were not "reasonable". ${ }^{19}$

El juez elude dar una sentencia sin pruebas suficientes. Y en el cuento, el lector se encuentra en una situación parecida. Solo que, aunque a ambos se les ha escamoteado pruebas contundentes, su finalidad es diferente. El juez no sentencia, pero el lector, en su fuero interno, sí lo hace. Obviamente, no se condena el alma del lector, bajo la perspectiva cristiana, pero sí se despierta una conciencia respecto al valor y la importancia de la interpretación, y la asunción de responsabilidad de la misma. No es el autor, ni ninguna otra institución la que interpreta el cuento: es el lector, a solas, quien asume esa responsabilidad. Entonces puede ser posible que el lector vuelva al texto

18. Ibíd., 113.

19. James Q. Whitman, "The Origins of 'Reasonable Doubt'”, Faculty Scholarship Series, Paper 1 (2005), 〈http://digitalcommons.law.yale.edu/fss_papers/1〉. 
para tratar de encontrar algún sentido oculto, o que empiece a hacer conjeturas como las que se han hecho páginas atrás.

Si advertimos que no se puede homologar el mundo de la realidad con el mundo de la ficción -un juicio siempre será diferente a un cuento, aunque este lo represente-, el propósito de ese escamoteo de pruebas y la exacerbación de la ambigüedad lo que buscan es que no se olvide el cuento. Así como el in dubio pro reo defiende la inocencia del acusado y salva el alma del juez sin pruebas o con pruebas imperfectas, en la literatura el vacío ficcional y la duda salva la autonomía del lector y lo fuerza a interpretar. Pero mientras al primero le permite seguir adelante y pasar a otra cosa, en el segundo, en el lector, se lo retiene con la interpretación. Así no se borra el cuento, se lo fija en su irresolución.

Este atributo de incompletud es una de las características del cuento moderno, en los que no hay ninguna moraleja que resuelva el sentido. Kurosawa sí la aplica en su película, donde se resuelve el enigma con una interpretación y hasta hay moraleja final. Esta irresolución en la literatura es la de escritores enigmáticos como Kafka, Cortázar o Raymond Carver, y en la que trabaja la estética de la recepción potenciando el papel del lector. Akutagawa sigue esta línea y la profundiza haciendo coincidir dos procedimientos que se potencian mutuamente. Los testimonios no son simples monólogos, van dirigidos a un narratario, que no es cualquiera sino un policía. El narrador es sospechoso o no fiable en la medida que tenga mayor o menor peso el narratario, y que el lector adquiera la destreza para tenerlo presente. Así el cuento abre más posibilidades de lectura. Lo irresuelto de la historia es una promesa de apertura de la recepción y de un lector mucho más activo. Lo que llamaría el principio del in dubio pro lector.

\section{BIBLIOGRAFÍA}

Akutagawa, Ryunosuke. Kappa. Los engranajes. Prólogo de Jorge Luis Borges. Buenos Aires: Mundonuevo, 1959.

—.Rashomón y otros cuentos. Madrid: Miraguano, 1987.

-.Belleza de lo brutal (Yasei No Utsukushisa): diez cuentos. Prólogo de Haruki Murakami. Barcelona: Días contados, 2011.

Beccaria, Cesare. De los delitos y de las penas. Madrid: Trotta, 2011.

Booth, Wayne C. The rethoric of fiction (1961). London: The University of Chicago Press, 1983.

Davis, Blair, Robert Anderson y Jan Walls, eds. Rashomon Effects: Kurosawa, Rashomon and Their Legacies (Routledge Advances in Film Studies). Abingdon: Routledge, 2015. 
Foucault, Michel. La hermenéutica del sujeto: curso en el Collége de France (1981-1982). Buenos Aires: Fondo de Cultura Económica, 2002.

- El gobierno de sí y de los otros: curso en el Collége de France (1982-1983). Buenos Aires: Fondo de Cultura Económica, 2009.

Gelio, Aulo. Noches áticas. Tomo II. Introducción, traducción, notas e índices de ManuelAntonio Marcos Casquero y Avelino Domínguez García. León: Universidad de León-Secretariado de Publicaciones, 2006.

Genette, Gérard. Discours du récit. París: Éditions du Seuil, 2007.

Martin, Mary Patricia, y James Phelan. “The Lessons of 'Weymouth': Homodiegesis, Unreliability, Ethics, and The Remains of the Day". En Narratologies: New Perspectives on Narrative Analysis, editado por David Herman, 88-109. Columbus: Ohio State University Press, 1999.

Nünning, Ansgar. "Reconceptualizing Unreliable Narration: Synthesizing Cognitive and Rhetorical Approaches". En A Companion to Narrative Theory, editado por James Phelan y Peter J. Rabinowitz. Malden: Blackwell Publishing, 2005.

Whitman, James Q. “The Origins of 'Reasonable Doubt' ”. Faculty Scholarship Series, Paper 1 (2005). 〈http://digitalcommons.law.yale.edu/fss_papers/1〉.

Yourcenar, Marguerite. Mishima o la visión del vacio. Barcelona: Seix Barral, 1985. 


\title{
ANEXO: \\ EN UN BOSQUECILLO
}

\author{
Ryunosuke Akutagawa ${ }^{1}$
}

\section{TESTIMONIO DE UN LEÑADOR ANTE EL COMISARIO MAYOR DE POLICÍA}

Sí, señor. Fui yo quien encontró el cadáver. Había salido de mañana a talar como siempre la cuota diaria de cedros cuando encontré el cadáver en un soto que hay en una depresión de las montañas. ¿El lugar preciso? A unos ciento cincuenta metros del camino de coches de Yamashina. Un bosquecillo apartado de cedros y bambú.

El cadáver yacía boca arriba con el quimono azul claro y una cofia estilo Kyoto toda arrugada. La hoja de la espada le había traspasado el pecho de un solo golpe. A su alrededor, cañas de bambú con las flores salpicadas de sangre. No, la sangre ya no corría. Creo que la herida estaba seca. Y también había un moscardón prendido a la herida que apenas me sintió llegar.

¿Que si vi una espada o algo por el estilo?

No, señor, no vi nada. Solo una soga al pie de un cedro que por ahí había. Y..., bueno, además de la soga me encontré un peine. Eso es todo. Parece que se libró una batalla antes de que lo asesinaran porque a su alrededor se veía la yerba pisoteada y las cañas de bambú estaban desbaratadas.

¿Que si había un caballo cerca?

No, señor. Es difícil que un hombre se meta por esos matorrales. Imagínese entonces un caballo.

\section{TESTIMONIO DE UN BONZO AMBULANTE ANTE EL COMISARIO MAYOR DE POLICÍA}

¿La hora? Sin duda que hacia el mediodía de ayer, señor. El pobre desdichado iba por el camino de Sekiyama a Yamashina. Caminaba rumbo a Sekiyama seguido por una mujer a caballo que ahora sé que era su esposa. Iba velada con un pañuelo amarrado a la cabeza que la protegía de cualquier mirada indiscreta. Solo alcancé a ver el

1. Cuento publicado por Ryunosuke Akutagawa en 1922. 
color de la ropa, su vestimenta lila. El caballo era un roano de magníficas crines. ¿La estatura de la mujer? Pues sería un metro veinticinco. Como soy sacerdote budista no me fijé con detenimiento. Bueno, el hombre iba armado de una espada, arco y flechas. Y recuerdo que llevaría unas veinte flechas en el carcaj.

En ningún momento pude imaginarme que ése sería su destino. En verdad la vida del hombre es efímera como el rocío matutino o el relámpago. No tengo palabras para expresar la pena que me embarga.

\section{TESTIMONIO DE UN GENDARME ANTE EL COMISARIO MAYOR DE POLICÍA}

¿El hombre a quien detuve? Es un notorio forajido llamado Tajomaru. Cuando lo prendí se acababa de caer del caballo. Lo encontré gimiendo de dolor en el puente de Awataguchi. ¿La hora? Eran las primeras horas de anoche. Hago constar que el otro día intenté detenerlo pero desgraciadamente se me escapó. Llevaba un quimono de seda azul de Prusia y un espadón sin repujar. Y como pude apreciar, por ahí andaban regados el arco y las flechas. Pues, ¿no dice que este arco y las flechas se parecen a las del muerto? Entonces Tajomaru debe ser el asesino. El arco, guarnecido con tiras de cuero, el carcaj de laca negra, las diecisiete flechas con plumas de halcón: creo que se había apoderado de todo. Sí, señor, el caballo que dice era un roano de magnífica crin. Pasado el puente de piedra me encontré el caballo pastando al borde del camino con su larga rienda suelta. Sin duda que la Providencia hizo que el caballo lo tumbara.

De todos los asaltantes que merodean por Kyoto, Tajomaru es quien más tribulaciones ha traído a las mujeres de la ciudad. El otoño pasado una mujer casada que se encontraba en la ladera norte del monte Pindora (por lo que se colige que había venido de visita al Templo Toribe), cayó asesinada con una muchacha. Se sospecha que también fue Tajomaru. Si él es el delincuente que asesinó a ese hombre, no quiero ni pensar lo que habrá hecho con su mujer. Ruego a su Excelencia que investigue bien este asunto.

\section{TESTIMONIO DE UNA VIEJA}

\section{ANTE EL COMISARIO MAYOR DE POLICÍA}

Sí, señor, ese es el cadáver del hombre que se casó con mi hija. No es natural de Kyoto. Era samurai del poblado de Kokufu, provincia de Wakasa. Se llamaba Kanazawa no Takehiko y tenía veintiséis años. Era de buen carácter, por lo que estoy segura de que no hizo nada que pudiera enfurecer a nadie.

¿Mi hija? Se llama Masago y tiene diecinueve años. Una muchacha impetuosa, llena de vida, aunque no me cabe la menor duda que nunca conoció a otro hombre que 
no fuera Takehiko. Rostro pequeño, ovalado, tez oscura y con un lunar en el rabillo del ojo izquierdo.

Takehiko salió ayer con mi hija rumbo a Wakasa. ¡Qué desdicha que tuvieran un final tan triste! ¿Qué ha sido de mi hija? Me resigno a perder a mi yerno pero el paradero de mi hija me tiene desvelada. Por Dios, no paren hasta encontrarla. Cómo odio al Tajomaru ese o como se llame el ladrón. No solo mi yerno, sino también mi hija... (Los sollozos ahogaron sus últimas palabras).

\section{CONFESIÓN DE TAJOMARU}

A él lo maté, pero a ella no. ¿Que dónde está? Yo qué sé. Un momento, un momento. No hay tortura que me vaya a hacer confesar lo que no sé. Ahora que las cosas han llegado a este extremo lo diré todo.

Ayer, pasado el mediodía, me encontré a esa pareja. Justo cuando un golpe de viento le alzó el pañuelo para que le viera de refilón la cara. En unos instantes volvió a quedar velada. Tal vez uno de los motivos que me llevaron a matada fue que parecía un Bodisatva. En aquel mismo instante decidí apresada, aunque tuviera que matar al hombre.

¿Por qué? Opino que matar no es tan trascendental como piensan. Cuando se aprisiona a una mujer no queda más remedio que matar al hombre. A la hora de matar empleo la espada que llevo a un costado. ¿Soy el único que mata en el mundo? Ustedes, ustedes no usan espadas. Todo lo contrario; matan con el poder, con el dinero. A veces matan gente con el pretexto de hacerle un favor. Es verdad que no derraman sangre. Es verdad que la gente conserva su buena salud, aunque después de todo la hayan matado. No es fácil decidir quién de nosotros es más ruin (Sonrisa irónica).

Me gustaría, no obstante, hacer prisionera a una mujer sin tener que matar a su marido. Por eso me había propuesto atraparla haciendo lo posible por no matarlo a él. Pero es algo imposible de lograr en la ruta de coches de Yamashina. Por eso me las ingenié para que la pareja se adentrara en las montañas.

Nada más fácil. Me volví su compañero de viaje, diciéndoles que en la montaña había un túmulo antiguo que había excavado, donde hallé una buena cantidad de espejos y espadas. Además, les dije haber enterrado el botín en un bosquecillo detrás de la montaña y que estaba dispuesto a venderlo a quien lo quisiera por un precio muy bajo. Ya ve... la avaricia rompe el saco, ¿verdad? El hombre cayó en la trampa sin darse cuenta. A la media hora los dos guiaban conmigo sus cabalgaduras rumbo a la montaña.

Cuando el hombre estaba delante del bosquecillo les dije que el botín se encontraba enterrado ahí mismo y les pedí que me siguieran. Él no se opuso; la avaricia lo 
cegaba. La mujer dijo que se quedaría esperando montada a caballo. Era lo lógico, a la vista de un bosquecillo tupido. Lo cierto es que el plan me iba saliendo como hecho a medida, de modo que me adentré con el hombre dejando sola a la mujer.

Durante parte del trayecto el bosquecillo es de bambú. A cincuenta metros hay un macizo un poco ralo de cedros. El lugar perfecto para mis fines. Adentrándome en la espesura le mentí sin que se diera cuenta, diciéndole que el tesoro estaba enterrado entre los cedros. En seguida se adelantó a duras penas rumbo a un delgado cedro que se veía a la salida del bosquecillo. Pasado un rato el bambú había empezado a ralear, hasta que llegamos a un sitio donde los cedros crecían en hilera. Nada más llegar lo agarré por la espalda. Aunque era un experto espadachín y un hombre de constitución muy fuerte, la sorpresa lo desarmó. En un santiamén lo tenía amarrado al pie de un cedro. ¿De dónde saqué la soga? A Dios gracias, como soy ladrón, llevaba una soga porque en cualquier momento me tengo que trepar a una pared. Claro que no me fue difícil impedir que gritara, pues lo amordacé con hojas caídas de bambú.

Ultimado este asunto me acerqué a la mujer para pedirle que viniera a verlo porque parecía que de pronto se había enfermado. Ni que decir tengo que la estratagema surtió también efecto. La mujer, luego de quitarse el sombrero de enea, penetró guiada de mi mano en lo más tupido del bosquecillo. En el preciso instante en que vio a su marido sacó un espadín. En mi vida vi a una mujer de carácter más violento. Si no hubiese estado en guardia me atraviesa el costado. Esquivé el golpe pero ella siguió tratando de herirme. Pudo haberme herido a fondo o matado. Pero yo soy Tajomaru. Conseguí arrebatarle el espadín sin haber tenido que desenvainar la espada. Sin un arma la mujer más resuelta del mundo está indefensa. Por fin pude saciarme sin tener que matar al marido.

Sí... sin tener que quitarle la vida. No quería la vida. No quería matarlo. Estaba a punto de salir huyendo y dejar a mis espaldas a la mujer hecha un mar de lágrimas cuando vi que me asía desesperadamente del brazo. Balbuciendo me imploró que matara al marido o que yo me matara. Dijo que para ella era peor que la muerte que dos hombres conocieran su vergüenza. Ahogándose me dijo de golpe que quería ser la mujer del que quedara vivo. En ese momento se apoderó de mí un deseo incontenible de matarlo (Sombría agitación).

Dicho de este modo seguro que parezco más cruel que usted. ¡Pero si hubiera visto su rostro! Sobre todo, aquellos ojos ardientes. Mirándola fijamente comprendí que quería hacerla mía, aunque luego me matara una maldición. Quería que fuera mi mujer..., estaba obsesionado. No por pura lascivia, como podrá pensar. Si solo hubiera sido lascivia no me hubiera costado ningún trabajo derribarla ahí mismo y luego salir huyendo. Entonces no hubiera manchado mi espada con la sangre del marido. Sin embargo, cuando vi su rostro en aquel bosquecillo oscuro decidí no huir sin matarlo. 
No quería recurrir a procedimientos ilegítimos para hacerlo. Lo desaté, desafiándolo a medir armas (la soga que encontraron al pie del cedro la dejé yo ahí). Enfurecido, desenvainó la espada de ancha hoja. y como un relámpago se abalanzó enardecido sobre mí sin decir esta boca es mía. Ya saben como acabó el combate. Fue el golpe veintitrés..., no lo olvide, por favor. Todavía me cuesta trabajo creerlo. No hay nadie bajo el sol que haya cruzado veinte golpes de espada conmigo (Sonrisa jovial).

Al desplomarse me volví hacia ella bajando la espada ensangrentada. Cuál no sería mi asombro cuando vi que había desaparecido. ¿A dónde habría escapado? La busqué por el macizo de cedros. Me quedé escuchando pero solo se oían los estertores del moribundo.

Puede que al empezar el duelo ella haya salido huyendo por el bosquecillo en busca de ayuda. Pensándolo, decidí que era un asunto de vida o muerte para mí. Entonces, arrebatándole al moribundo la espada, el arco y las flechas, llegué jadeando al camino que atraviesa la montaña. Encontré su caballo pastando aún apaciblemente. ¿Qué sentido tiene desperdiciar palabras y relatar pormenorizadamente todo lo demás? Baste decir que al entrar al pueblo ya me había desembarazado de la espada. No tengo otra cosa que confesar. Sé que de todos modos mi cabeza colgará entre cadenas; pida pues la pena de muerte (Actitud desafiante).

\section{CONFESIÓN DE UNA MUJER QUE IBA DE VISITA AL SANTUARIO SHIMIZU}

El hombre del quimono azul de seda, luego de violarme, se echó a reír mirando desvergonzadamente a mi marido, a quien tenía atado a un árbol. ¡Qué terror habrá sentido el pobre! Por más que intentara librarse, en su desesperación la soga se le incrustaba cada vez más a la carne. A pesar de mí misma corrí dando tumbos a ayudarlo. O más bien intenté ir a su encuentro pero el asaltante me derribó. En ese preciso instante relució en la mirada de mi marido un fulgor indescriptible. Algo imposible de comunicar..., el brillo de sus ojos todavía me hace temblar. Esa mirada fulgurante de mi marido, imposibilitado de hablar, me reveló de un golpe todo su corazón. El resplandor de sus ojos no era ni de rabia ni de sufrimiento..., solo una luz fría, una mirada de desprecio. Herida, más por su mirada que por la embestida del bandido, me puse a chillar enloquecida y, sin darme cuenta, me desmayé.

Poco después recobré la conciencia y vi que el hombre del quimono azul había desaparecido. Solo vi a mi marido atado todavía al pie del cedro. Me incorporé con dificultad de entre las grandes hojas de bambú y lo miré; la expresión de sus impertérritos ojos era la misma. 
Había odio acumulado en su mirada desdeñosa. Vergüenza, pesadumbre y rabia... No sé decir lo que sentí en aquel momento. Hincándome de rodillas me le acerqué.

"Takejiro", le dije. "Puesto que han sucedido estas cosas no puedo seguir a tu lado. Estoy dispuesta a morir..., pero tú también debes morir. Presenciaste mi vergüenza. No puedo dejarte vivo".

No pude hablar más. Él me seguía mirando con asco y desprecio. Busqué su espada con el corazón haciéndoseme pedazos. Seguro que el ladrón se la había llevado. No pude encontrar la espada en el bosquecillo, ni el arco y las flechas. Por suerte mi espadín yacía a mis pies. Alzándolo por encima de la cabeza exclamé una vez más: "Entrégame la vida. Y yo te seguiré".

Al oír esas palabras movió los labios con dificultad. Como tenía la boca atiborrada de hojas, su voz era, por supuesto, inaudible. Pero entendí de un golpe sus palabras. En su desprecio, aquella mirada imperturbable decía: "Mátame." Sin comprender exactamente lo que hacía enterré el espadín en su pecho, atravesándole el quimono lila.

De nuevo, en esta ocasión, debí perder el conocimiento. Al recobrarlo él ya había expirado, amarrado al árbol. Un rayo último de sol penetraba el macizo de cedros y bambú, iluminando la palidez de su rostro. Tragándome los sollozos desaté aquel cuerpo exánime. Y..., y lo que me sucedió después es algo que no tengo fuerzas para contar. En todo caso, no tuve el valor de matarme. Me enterré el espadín en la garganta, traté de ahogarme en una laguna al pie de la montaña, traté de matar me de muchos otros modos. Incapaz de lograrlo, vivo deshonrada. (Sonrisa desolada.) Despreciable que soy, incluso la propia Kwannon, diosa de piedad, debe haberme abandonado. Maté a mi propio marido. El ladrón me violó. ¿Qué puedo hacer? ¿Qué puedo yo... yo...? (Momentos después rompe a llorar).

\section{VERSIÓN DEL OCCISO A TRAVÉS DE UN ESPIRITISTA}

Luego de violar a mi mujer el ladrón, sentado aquí mismo, la empezó a consolar. Claro que yo no podía hablar. Estaba firmemente maniatado al pie de un cedro. Sin embargo, muchas veces le guiñé el ojo como para decirle: "No te dejes engatusar por el ladrón". Era más o menos lo que le quería comunicar. Pero mi mujer, en su abatimiento, sentada entre las hojas de bambú, mantenía la mirada fija en el regazo. Al parecer escuchaba al ladrón. Los celos me consumían. Entretanto, aquel granuja pasaba astutamente de un asunto a otro. Finalmente, el ladrón se atrevió a presentar su desvergonzada propuesta: "Después de deshonrada no es posible que te lleves bien con tu marido. Entonces, ¿por qué no te casas conmigo? El amor fue lo que me llevó a tratarte violentamente". 
Mientras el criminal hablaba mi mujer levantó la vista como en un trance. Nunca la vi tan bella como en aquel momento. ¿Qué le contestó mi agraciada mujer mientras yo seguía atado al árbol? Perplejo, no puedo recordar sus palabras sin que la rabia y los celos me quemen. La oí decir claramente: "Llévame entonces contigo adonde vayas".

Este no es su único pecado. Si solo se tratara de eso no me atormentaría tanto la oscuridad. Saliendo del bosquecillo y como en un sueño, su mano enlazada a la del ladrón, vi que se ponía repentinamente pálida y señalándome atado al cedro decía: “¡Mátalo! Mientras viva no podré casarme contigo. ¡Mátalo!”, gritó varias veces como si hubiera perdido la razón. Incluso hoy sus palabras amenazan con precipitarme al oscuro abismo sin fondo. ¿Se ha oído jamás algo tan odioso en boca de un ser humano? ¿Alguna vez hirieron oído humano palabras tan perversas? ¿Tan siquiera una vez esas... (Repentina exclamación de desdén). Ante sus palabras, el propio ladrón palideció. "Mátalo", gritó colgándose de sus brazos. Mirándola fijamente, calló..., cuando, sin darme tiempo a meditar una respuesta la derribó entre las hojas de bambú (De nuevo exclamación desdeñosa). Cruzándose mudamente de brazos me miró y dijo: "Decide. ¿La mato o la dejo viva? Dímelo con un movimiento de cabeza". ¿Matarla? Sus palabras, en mi opinión, lo redimen.

Mientras vacilaba oí un alarido y la vi adentrarse en el bosquecillo. El ladrón había intentado en aquel momento asirla del brazo pero ni siquiera pudo cogerle una manga del quimono.

Después que ella huyó, él agarró mi espada, el arco y las flechas y de un golpe me cortó las ataduras. Recuerdo que dijo entre dientes: "La suerte está echada". Fue entonces que se apartó del bosquecillo. Todo quedó en silencio. O no. Oí a alguien llorar. Mientras acababa de desatarme seguí atento hasta que vi que era mi propio llanto (Largo silencio).

Me incorporé extenuado al pie del cedro. Delante de mí refulgía el espadín que había dejado caer mi mujer. Recogiéndolo me herí el pecho. Un coágulo de sangre me subió a la boca, pero no sentí el más mínimo dolor. Al enfriarse mi pecho todo se cubrió del silencio de los muertos en sus tumbas. ¡Qué profundo silencio! No se oyó trinar un pájaro sobre esta tumba perdida en la cima de una montaña. Solo una triste luz flotaba sobre los cedros y la montaña. Paulatinamente la luz disminuyó hasta que los cedros y el bambú se desvanecieron. Echado en aquel sitio, me dejé envolver por el silencio.

Entonces vi que alguien se arrastraba hacia mí. Intenté ver quién era. Pero me rodeaba la oscuridad. Alguien... y ese alguien sacó suavemente con mano invisible el espadín que me había enterrado en el pecho. Al mismo tiempo la sangre se me agolpó en la boca. Y de una vez por todas me hundí en la oscuridad del espacio. 